\title{
Genetic Evaluation of Localized Prostate Cancer in a Cohort of Forty Patients: Gain Of Distal 8q Discriminates Between Progressors and Nonprogressors
}

\author{
Herman van Dekken, Janneke C. Alers, Irma A.A.J. Damen, Kees J. Vissers, \\ Pieter-Jaap Krijtenburg, Robert F. Hoedemaeker, Mark F. Wildhagen, \\ Wim C.J. Hop, Theodorus H. van der Kwast, Hans J. Tanke, and Fritz H. Schröder \\ Departments of Pathology (HvD, JCA, IAAJD, KJV, P-JK, RFH, THvdK), Urology (MFW, FHS), and Epidemiology \\ and Biostatistics (WCJH), Erasmus Medical Center, University Medical Center Rotterdam, Rotterdam, and \\ Laboratory for Cytochemistry and Cytometry (HJT), Department of Molecular Cell Biology, Leiden University \\ Medical Center, Leiden, the Netherlands
}

\begin{abstract}
SUMMARY: Over-representation of sequences on chromosome 7 and 8 have been reported to be associated with aggressive behavior of prostate cancer. In this study we have performed a molecular cytogenetic survey by comparative genomic hybridization of a cohort of 40 prostate cancer patients, consisting of 20 progressors and 20 nonprogressors, after radical surgery for localized adenocarcinoma. Progression was defined as a biochemical relapse, ie, an elevation in prostate-specific antigen level in the serum. The mean follow-up after prostatectomy for the progressor group was 10.6 years, for the nonprogressor group, 9.1 years. Using comparative genomic hybridization, we found that progressors harbored on average more aberrations than nonprogressors. Gains were especially more prominent among progressors $(p<0.05)$, whereas a statistical trend was detected for losses $(p=0.10)$. As a consequence we examined all chromosome arms separately. The frequencies of loss for areas known to be frequently deleted in prostate cancer, such as $6 q, 8 p$, or $13 q$, were not different between the two groups. A tendency was observed for more frequent gain on $3 q$ in the progressor group $(p=0.09)$. However, gain of $8 q$ (minimal overlapping region at 8q24-qter) was significantly more frequent in the progressor group $(p=0.04)$. This biomarker retained its significance when adjusted for the factors age, tumor grade, tumor stage, resection margin status, and preoperative prostate-specific antigen level. In conclusion we have created a map of genetic changes in progressive and nonprogressive prostatic carcinomas. Importantly, the presence of gain of distal $8 q$ markedly reduced the progression-free survival, suggesting a clinical role for $8 q$ gain in assessing the malignant potential of localized prostatic adenocarcinoma. (Lab Invest 2003, 83:789-796).
\end{abstract}

\begin{abstract}
$P$ rostate cancer is the most commonly diagnosed male malignancy and the second leading cause of cancer-related death in men in Western countries. This also counts for the Netherlands, where the number of cases increased from 4185 in 1989 to 6402 in 1997. In 1997 it ranged per 100,000 individuals from 130 cases at the age of 50 to 54 to 814 cases at the age of 80 to 84 (Visser et al, 2001). Population-based prostate-specific antigen (PSA) screening has resulted in a marked increase in the early detection of prostate cancer (Potosky et al, 1995; Schröder et al, 1998). It remains unclear, however, what fraction of these newly diagnosed cases represents subclinical disease, which might not require aggressive treatment.
\end{abstract}

DOI: 10.1097/01.LAB.0000074889.76221.49

Received December 5, 2002.

Address reprint requests to: Dr. H. van Dekken, Department of Pathology, Josephine Nefkens Institute, Erasmus University Rotterdam, P.O. Box 1738, 3000 DR Rotterdam, the Netherlands. E-mail: vandekken@path.fgg.eur.nl
Therefore, it is important to discriminate indolent tumors from cancers with aggressive and progressive potential. Current methods for assessing the prognosis of prostate cancer, such as clinical and pathological staging and histopathologic grading, fail to provide consistent predictive information regarding clinical outcome and therapeutic strategy in individual cases (Gittes, 1991; Gleason, 1992). In the past decades, ample information has been published regarding the genetics of prostatic adenocarcinoma. However, genetic data concerning the biological behavior of prostate cancer are sparse.

Cytogenetic studies of prostatic adenocarcinoma have revealed trisomy of chromosome 7, del(7)(q22), del(8)(p21), del (10)(q24), and loss of the $Y$ chromosome (Brothman et al, 1991; Lundgren et al, 1992). $\mathrm{LOH}$ analyses have shown frequent loss on chromosome arms 3p, 6q, 7q, 8p, 9p, 10pq, 13q, 16q, 17q, and 18q (Cooney et al, 1996; Cunningham et al, 1996; Perinchery et al, 1999; Saric et al, 1999; Vocke et al, 1996). Some of these alterations were implicated in aggressive tumor behavior, eg, loss on $8 p, 16 q$, or $18 q$ 
(Li et al, 1999; Matsuyama et al, 2001; Ueda et al, 1997). Furthermore, comparative genomic hybridization $(\mathrm{CGH})$ analysis applied to a panel of both primary and recurrent tumors revealed losses of $8 p$ and $13 q$ in more than $30 \%$ of cases, whereas recurrent tumors showed gains of $8 q$ and of chromosomes 7 and $X$, as well as loss of $8 p$ in more than half of cases (Visakorpi et al, 1995). Furthermore, these recurrent tumors exhibited $8 q$ gain $>10$ times more often than the primary tumors. A CGH study of a panel of mostly regional lymph node metastases showed loss of $8 p, 10 q, 13 q$, $16 q$, and $17 p$, as well as gain of $1 q, 3 q, 8 q$, and $11 p$ sequences in $50 \%$ or more of tumors (Cher et al, 1996). FISH studies revealed numerical alterations of chromosomes 7, 8, 10, 16, 17, 18, X, and $Y$ (reviewed in Brothman et al, 1999; van Dekken et al, 1997), as well as deletions and amplifications of specific chromosomal regions, eg, 8p22 (Huang et al, 1996; Macoska et al, 1994) and the MYC region on $8 q 24$ (Bubendorf et al, 1999; Jenkins et al, 1997).

We and others (Alcaraz et al, 1994; Alers et al, 1997, 1998, 2000; Sato et al, 1999; Takahashi et al, 1994) have identified alterations of chromosomes 7 or 8 as potential tumor progression markers. A study by our group showed that gains, especially of chromosome $7 p q$ or $8 q$ sequences, were potent genetic markers for adverse prognosis in primary tumors of patients after radical prostatectomy (Alers et al, 2000). A recent investigation revealed that these chromosomal changes can also be found in a subgroup of small tumors detected in screening programs (Alers et al, 2001). All these data warranted further evaluation of genetic markers in a group of patients with localized prostate cancer. Here we present genetic data of a cohort of 40 patients consisting of 20 progressors and 20 nonprogressors, with long-term follow-up after radical surgery.

\section{Results}

We have performed a molecular cytogenetic survey by CGH of a cohort of 40 prostate cancer patients consisting of 20 progressors and 20 nonprogressors after radical surgery for localized adenocarcinoma. These two groups of patients were found to have similar characteristics for age, preoperative PSA, pathologic grade, clinical stage, and resection margin status (Table 1). The mean follow-up after prostatectomy for the progressor group was 10.6 years, for the non-progressor group, 9.1 years (range for both groups, 7 to 15 years). We found by CGH that progressors harbored on average more aberrations than nonprogressors $(p=0.06)$. Gains were more frequent among progressors ( $p<0.05)$; a statistical trend was detected for losses $(p=0.10)$. In multivariate analyses these differences remained intact when adjusted for tumor grade, stage, and preoperative PSA. Subsequently each chromosome arm was compared for differences between progressors and nonprogressors. An overview of the $\mathrm{CGH}$ imbalances in both groups is depicted in Figure 1, the alterations are listed in Table 2. Frequent loss $(>10 \%$ of cases; Fig. $1 \mathrm{~A})$ in the progressor group was seen on $13 q(60 \%), 8 p(50 \%)$, $6 q(30 \%), 5 q(25 \%), 16 q(20 \%), 10 q, 17 p, 18 q$, and $Y$ (all 15\%), whereas frequent gain was observed on $8 q$ (35\%), 3q $(30 \%), 20 q$, and $X$ (both $15 \%)$. In the

Table 1. Clinical, Histopathologic and Genetic Data of a Cohort of 20 Progressors and 20 Nonprogressors after Radical Surgery

\begin{tabular}{llll}
\hline \multicolumn{1}{c}{$N=40(20+20)$} & Progressors & Nonprogressors & value \\
\hline Mean age at operation (range; years) & $62.9(47-72)$ & $62.0(49-72)$ & 0.51 \\
Median preoperative PSA (range; $\mathrm{ng} / \mathrm{ml})$ & $14.9(0.7-108)$ & $9.6(2.2-21.8)$ & 0.16 \\
aPathologic grade & $10 \% \mathrm{G} 5$ & $5 \% \mathrm{G} 5$ & 0.46 \\
& $15 \% \mathrm{G} 6$ & $40 \% \mathrm{G} 6$ & \\
& $75 \% \mathrm{G} 7$ & $50 \% \mathrm{G} 7$ & \\
'PPathologic stage & & $5 \% \mathrm{G} 8$ & 0.36 \\
& $35 \% \mathrm{~T} 2$ & $50 \% \mathrm{~T} 2$ & \\
Resection margin & $40 \% \mathrm{~T} 3$ & $35 \% \mathrm{~T} 3$ & 1.00 \\
Mean no. aberrant chromosomes/tumor & $25 \% \mathrm{~T} 4$ & $15 \% \mathrm{~T} 4$ & $0.06^{c}$ \\
Mean no. chromosomes with gain/tumor & $30 \%$ positive & $35 \%$ positive & $0.047^{d}$ \\
Mean no. chromosomes with loss/tumor & 4.50 & 2.50 & $0.10^{c}$ \\
$+3 \mathrm{q}$ & 1.70 & 0.60 & $0.09^{c}$ \\
$-6 \mathrm{q}$ & 3.05 & 1.95 & 0.74 \\
$-8 \mathrm{p}$ & $30 \%$ & $5 \%$ & 0.75 \\
$+8 \mathrm{q}$ & $30 \%$ & $40 \%$ & $0.044^{d}$ \\
$-13 \mathrm{q}$ & $50 \%$ & $40 \%$ & 0.11 \\
\hline
\end{tabular}

PSA, prostate-specific antigen; T2, confined within prostate; T3, through prostatic capsule; T4, fixed or invades adjacent structures.

${ }^{a}$ Gleason score.

${ }^{b}$ TNM classification; all tumors NOMO.

${ }^{c}$ Detected trend $(0.05-0.10)$.

${ }^{a}$ Statistically significant $(<0.05)$. 


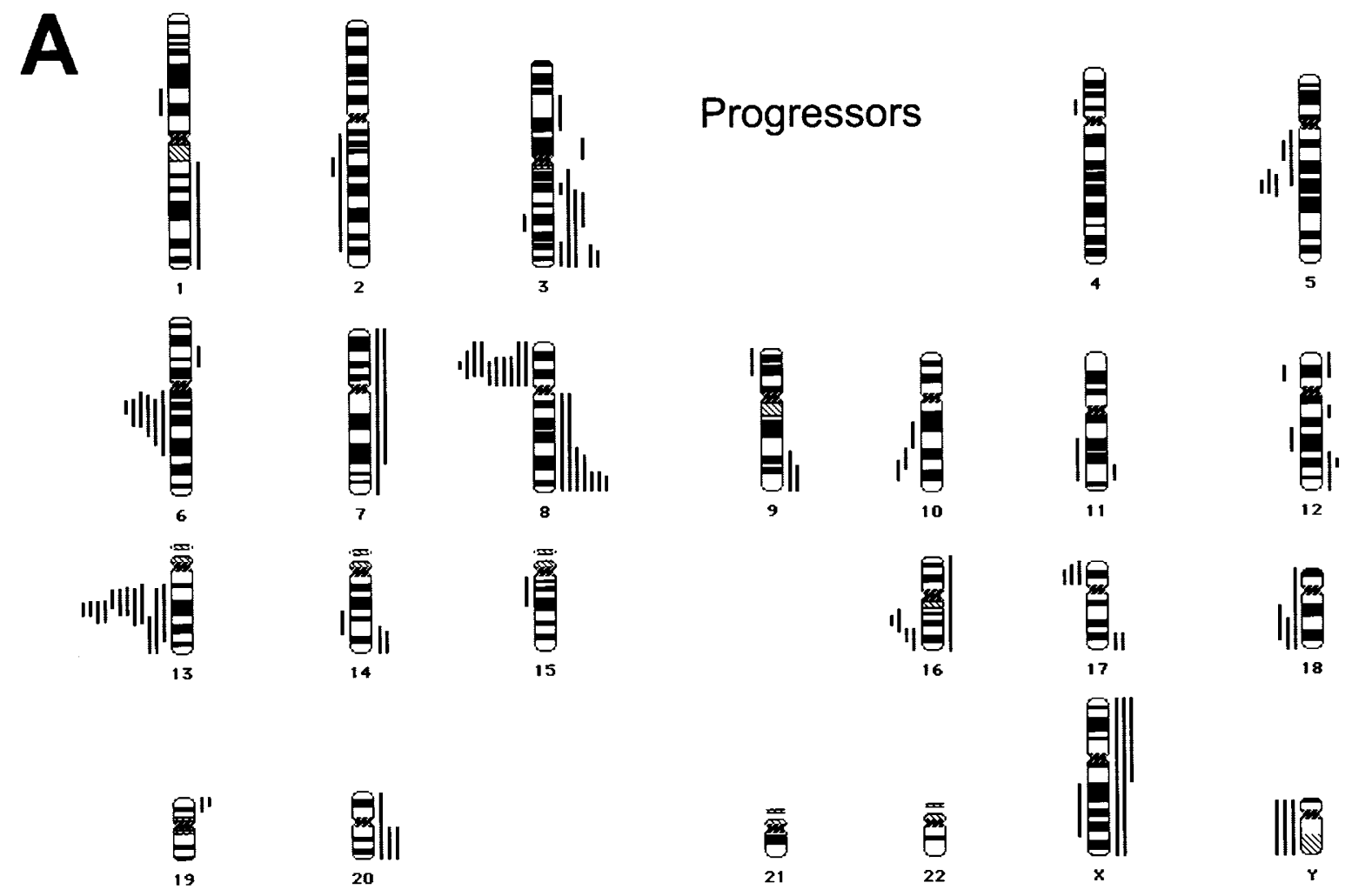

B
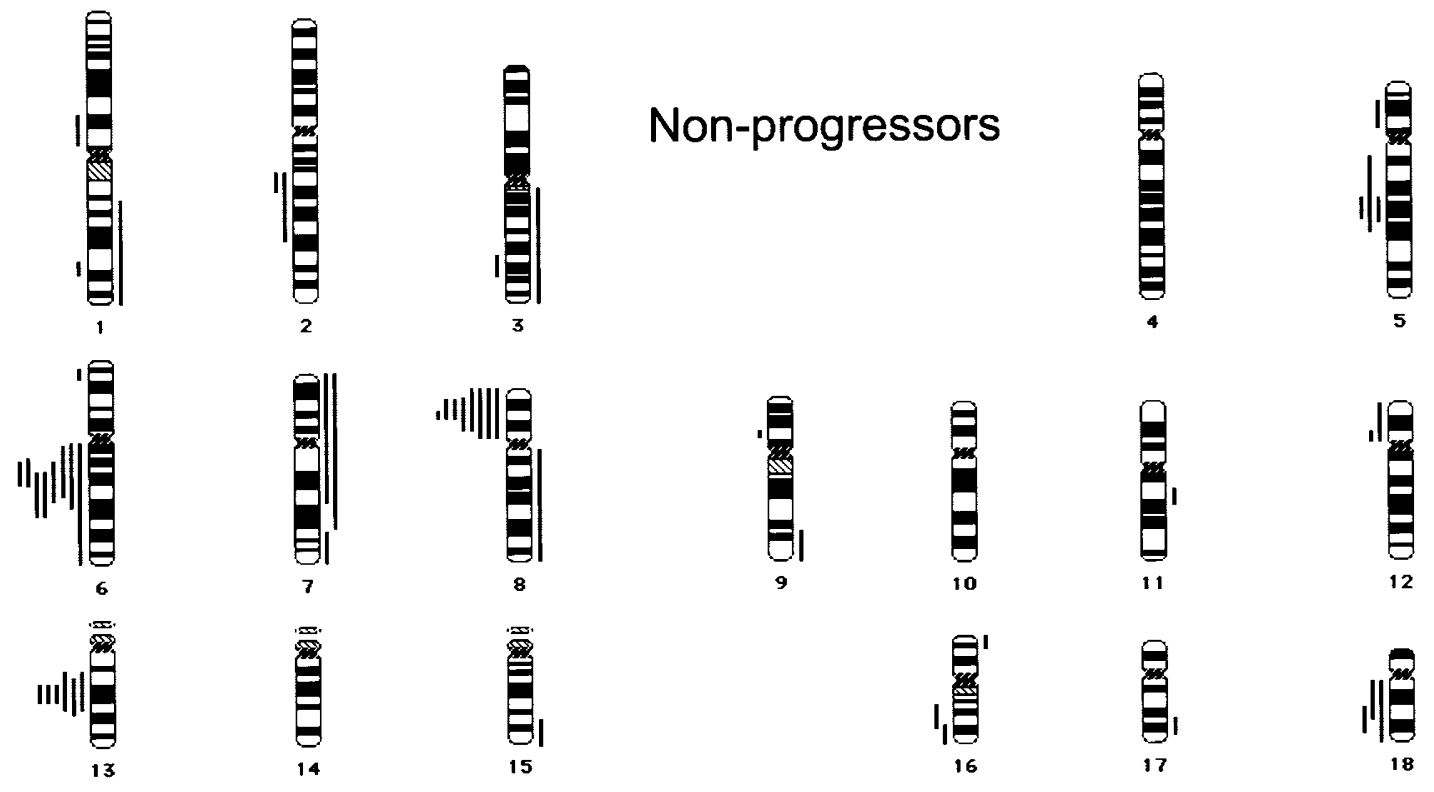

基
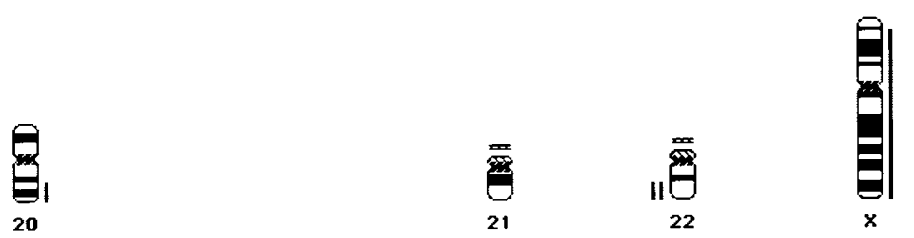

Figure 1.

Chromosomal ideograms showing the summary of DNA copy number changes, detected by CGH, in prostatic adenocarcinomas of 20 progressors (A) and 20 nonprogressors (B) after radical surgery for localized disease. Losses are displayed on the left of the chromosomal ideogram; gains are shown on the right. Note frequent gain of (distal) 8q in the progressor group, as compared with the nonprogressors. 
Table 2. Genetic Alterations in 20 Progressors and 20 Nonprogressors after Radical Prostatectomy

\begin{tabular}{|c|c|c|}
\hline $\begin{array}{l}\text { Progressor } \\
\quad N=20\end{array}$ & Loss & Gain \\
\hline 1 & $8 p 21,12 p 11.2-p 12$ & $3 p 12,3 q 21-q 25$ \\
\hline 2 & $13 q 21-q 22$ & \\
\hline 3 & & 8q24.1-qter \\
\hline 4 & $16 q 13-q 21$ & 3q26.3-qter, 8q22-qter \\
\hline 5 & 8p12-p22, 16q22-qter, 17p11.2-pter & \\
\hline 6 & $8 p 11.2-p 22,10 q 21-q 22$ & \\
\hline 7 & $6 q 13-q 16,8 p 11.2-p 22, Y$ & 7, 8q11.2-qter, 9q32-qter, 12p12-p13, 12q13, 12q22-ter, 16 \\
\hline 8 & $13 q 21-q 22$ & 19p13.3-pter \\
\hline 9 & $2 q 21-q 22,5 q 12-q 13,6 q 12-q 21,13 q 14-q 21$ & 20 \\
\hline 10 & $\begin{array}{l}2 q 12-q 36,6 q 13-q 15,8 p 12-p t e r, 10 q 24-q 25, \\
13 q 14-q t e r, 17 p 11.2-p t e r, 18 q 12-q 22\end{array}$ & 3q13.3-qter, 8q24.1-qter, 11q23, 14q24-qter, 17q24-qter, X \\
\hline 11 & 8p12-pter, 17p11.2-p12 & \\
\hline 12 & $8 p 11.2-p 21$ & \\
\hline 13 & $\begin{array}{l}\text { 6q12-q16, 8p11.2-pter, 13q13-q22, 16q22-q23, } \\
18 q 21-q \text { ter }\end{array}$ & $12 q 23, X$ \\
\hline 14 & $\begin{array}{l}4 p 12-p 14,5 q 11.2-q 21,10 q 23-q 24,13 q 21 \\
14 q 22-q 24,15 q 11.2-q 21,16 q 12.1-q 22,18 \\
\times q 21-q 26\end{array}$ & $\begin{array}{l}\text { 1q21-qter, 1q31-qter, 3p14-p21, 3q13.3-q21, 3q26.2-qter, } \\
8 q 23-q t e r, 9 q 22-q t e r, 17 q 23-q t e r, 20 q 11.2-q t e r, \\
\text { Xp11.2-p22.2, Xq12-q13 }\end{array}$ \\
\hline 15 & $\begin{array}{l}5 q 15-q 22,6 q 13-q 22,8 p 11.2-p t e r, 11 q 14-q 23 \\
12 q 15-q 21,13 q 14-q 21\end{array}$ & 3q12-qter, 7p11.2-pter, 7q11.2-q31, 8q24.1-qter \\
\hline 16 & $6 q 12-q 24,13 q 13-q 32$ & 3q27-qter \\
\hline 17 & $13 q 21, Y$ & \\
\hline 18 & $1 p 21-p 22,3 q 24-q 25,5 q 14-q 21,13 q 14-q 31$ & 6p21.1-p21.3, 14q24-qter, 20q11.2-qter \\
\hline 19 & $8 p 11.2-p 22,13 q 13-q 21, Y$ & $8 q 11.2-q$ ter \\
\hline 20 & 9p21-pter, 13q22-qter, 5q21 & \\
\hline
\end{tabular}

\begin{tabular}{|c|c|c|}
\hline \multicolumn{3}{|c|}{ Nonprogressors } \\
\hline 1 & $6 q 14-q 16,8 p 21,18 q 11.2-q 21$ & \\
\hline 2 & $12 \mathrm{p} 11.2$ & \\
\hline 3 & 8p11.2-pter, 12p11.2-pter & \\
\hline 4 & $18 q 21-q 22,22 q 13$ & 1q23-qter, 11q13-q14, 15q24-qter \\
\hline 5 & 5p13-p14, 5q15-q22, 6q12-q22, Y & \\
\hline 6 & $13 q 21$ & \\
\hline 7 & $\begin{array}{l}\text { 1p13-p21, 1q32-q41, 2q21-q32, 5q12-q23, } \\
\text { 6p23-p24, 6q12-qter, 8p12-p22 }\end{array}$ & 3q11.2-qter, 7p11.2-pter, 7q11.2-q31 \\
\hline 8 & $6 q 11.2-q 21,13 q 21,22 q 13$ & \\
\hline 9 & $6 q 14-q 16, Y$ & $17 q 23-q 24$ \\
\hline 10 & $13 q 21$ & \\
\hline 11 & $6 q 14-q 22$ & \\
\hline 12 & 8p11.2-pter, 18q11.2-qter & \\
\hline 13 & $8 p 21-p 22,13 q 14-q 31$ & $\begin{array}{l}\text { 7p11.2-pter, 7q11.2-q22, 7q32-qter, } \\
\text { 16p13.2-pter, 20q13.1-qter }\end{array}$ \\
\hline \multicolumn{3}{|r|}{ 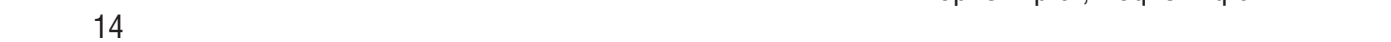 } \\
\hline 15 & $6 q 16-q 22$ & \\
\hline 16 & $8 p 21-p 22$ & \\
\hline 17 & & Xp11.2-p22.1, Xq12-qter \\
\hline 18 & $2 q 21-q 22,13 q 14-q 22$ & 9q32-qter \\
\hline 19 & 8p11.2-pter, 16q23-qter & \\
\hline 20 & $\begin{array}{l}5 q 15-q 21,6 q 16-q 22,8 p 12-p t e r, 13 q 14-q 22, \\
16 q 13-q 23\end{array}$ & 8q11.2-qter \\
\hline
\end{tabular}

nonprogressor group, frequent loss ( $>10 \%$ of cases; Fig. 1B) was detected on $8 p(40 \%), 6 q(40 \%), 13 q$ $(30 \%), 5 q$, and $18 q$ (both $15 \%)$. No frequent gains were seen in this group. Minimal overlapping regions for loss in both groups occurred at 5q21, 6q14-q16, $8 p 21,13 q 21$, and 18q21. A critical region for gain was seen only in the progressor group at 8q24.1-qter (Fig. 1). The frequencies of loss for areas known to be often 
deleted in prostate cancer, such as $5 q, 6 q, 8 p, 10 q$, $13 q$, or $16 q$, were not different between the two groups (Table 2). This also counted for gain on chromosome 7. A tendency was observed for more frequent gain on $3 q$ in the progressor group $(p=0.09)$. This tendency was lost in multivariate analysis. However, gain of $8 q$ (minimal overlapping region at $8 q 24.1$ qter) was significantly more frequent in the progressor group $(p=0.04)$. Importantly, multivariate analysis showed that this biomarker retained its significance when adjusted for the factors age, tumor grade, tumor stage, resection margin status, and preoperative PSA $(p<0.05)$. Finally, we found no significant associations between the presence of gain of $8 q$ and the standard prognostic factors (age, grade, stage, resection margin, and preoperative PSA).

\section{Discussion}

We have screened a cohort of progressive and nonprogressive prostate cancer patients, with a mean follow-up of about 10 years by $\mathrm{CGH}$, and disclosed gain of chromosome $8 \mathrm{q}$ as an independent biomarker for tumor progression. This was found after comparison of the two groups using the complete time interval. One could also investigate whether the time frame in which progression occurred was in keeping with the (minimal) follow-up of the nonprogressor group. In our series progression was seen within 6 years in 19 of the 20 progressive patients, whereas the minimal follow-up for the nonprogressors was 7 years. One patient became progressive after 9 years. Multivariate analysis for the presence of gain of $8 q$ using the 6 -year time frame, ie, with exclusion of the progressor after 9 years, again revealed retention of significance when adjusted for all of the standard prognostic factors. The minimal follow-up of 7 years therefore appeared an adequate time interval for detection of progression.

The spectrum of genetic changes found in this study are consistent with previous $\mathrm{CGH}$ investigations of prostatic cancer (Alers et al, 2000; Cher et al, 1996; Visakorpi et al, 1995). We specifically addressed the issue of differences between progressive and nonprogressive disease. We were further interested in aberrations of chromosomes 7 and 8 because gain of sequences on these chromosomes has been associated with aggressive and progressive behavior of prostatic adenocarcinoma. Previously we reported that gain of chromosome 7 or $8 q$ was inversely correlated with progression-free survival. In the present study, we were able to reduce the critical region that is implicated in prostate cancer progression to the distal region of chromosome $8 \mathrm{q}$.

Gain of $8 q$ has often been seen in metastases to the bone in association with 8p loss (Alers et al, 1997). This association suggests an isochromosome $\mathrm{i}(8 \mathrm{q})$ formation (Alers et al, 1997; Bova et al, 1993; Macoska et al, 1994). In addition we observed i(8q) formation by $\mathrm{CGH}$ analysis and karyotyping in two prostate cancer cell lines, PC 133 and PC 346 (unpublished data). PC 133 is a prostatic tumor cell line derived from a bone metastasis, whereas PC 346, derived from a primary prostatic tumor, displays rapid growth in mice (van Weerden et al, 1996). Gain of sequences on chromosome 8 is reported to be associated with high tumor grade and stage (Alers et al, 1997; Takahashi et al, 1994). The target gene for this gain is currently not known. Chromosome 8q24 harbors the MYC oncogene. Amplification of this region was detected in a subset of metastatic and recurrent tumors (Bubendorf et al, 1999; Jenkins et al, 1997; Nupponen et al, 1998) and was shown to correlate with the presence of regional lymph node metastases (van den Berg et al, 1995), as well as with poor prognosis (Alers et al, 2000; Sato et al, 1999). Recently, gain of EIF3S3, located at distal $8 \mathrm{q}$ and encoding a eukaryotic translation initiation factor, was found associated with high-grade and high-stage prostatic cancers (Saramaki et al, 2001). Furthermore, tumors with amplification of MYC appeared to have co-amplification of EIF3S3. Another candidate gene in this region may be the prostate stem cell antigen, mapping to $8 \mathrm{q} 24.2$, which is overexpressed in prostate cancer specimens and which overexpression is correlated with grade, stage, and androgen-independence (Reiter et al, 1998). A recent gene expression study concerning the $8 q 24$ region revealed eight overexpressed genes, including MYC (Tsuchiya et al, 2002). Finally, a variety of zinc finger proteins, genes often involved in cancerous processes, are mapped to 8q24 (see the genecards database of the Weizmann Institute, World Wide Web URL: http://bioinfo.weizmann.ac.il/cards).

Other differences between the two groups, but without statistical significance, included losses on $10 q, 13 q, 16 q, 17 p$, as well as gains on $3 q$ and $20 q$. Gain of chromosome $20 \mathrm{q}$, often involving the whole long arm, is frequently detected in high-grade, highstage neoplasms of various histologies (van Dekken et al, 1997). A trend was seen in our study for gain on 3q. This trend, however, was lost in multivariate analysis. Moreover, it was not feasible to assign a critical region of gain on this chromosome arm. Deletion of 13q21 and 16q23-q24 have been reported to be associated with metastatic behavior of prostate cancer (Dong et al, 2000; Li et al, 1999). The loss on 10q might be related to aberrations of PTEN, which have been described in high-stage prostate tumors (McMenamin et al, 1999). Also the recently described LAPSER1, a gene involved in cell growth regulation, might be related to the losses on $10 \mathrm{q}$ (Cabeza-Arvelais et al, 2001). Deletions on 17p likely involve TP53, a gene reported to be altered in a subgroup of prostatic carcinomas with poor prognosis (Quinn et al, 2000). Altogether these data are in keeping with the results of our investigation.

In conclusion, we have created a map of genetic changes in progressive and nonprogressive prostatic carcinomas. Gains of chromosomal sequences were more frequently distinguished in progressors. Specifically, the presence of gain of distal $8 q$ markedly reduced the progression-free survival. It is tempting to speculate that this might yield a probe to assess the malignant potential of localized prostatic carcinomas in the individual patient. However, the current findings 
are based on a relatively small number of patients. We are now screening a large number of tumors using both tissue and genomic DNA microarrays to further delineate the genes underlying aggressive characteristics of prostate cancer.

\section{Materials and Methods}

\section{Patient Data}

The prostate cancer panel consisted of 40 routinely processed, formalin-fixed, paraffin-embedded tissue blocks selected from the radical prostatectomy specimens of 20 progressors and 20 nonprogressors (Table 1). The mean age of the progressors at operation was 62.9 years (range, 49 to 72 years); the mean age of the nonprogressors was also 62.9 years (range, 47 to 72). None of the patients received endocrine or radiation therapy prior to operation. The tumors were pathologically staged according to the pTNM classification (Hermanek et al, 1997), and the specimens were graded according to the Gleason grading system (Gleason, 1992). Our panel originally consisted of 22 progressors and 22 nonprogressors. However, two cases from each group were discarded due to insufficient $\mathrm{CGH}$ results. Importantly, this did not influence the statistics of the cohort.

Follow-up study of the remaining 40 patients showed progression after radical prostatectomy in 20 cases. In 19 patients this occurred within 6 years, with one patient showing progression after 9 years (mean, 3 years). Progression was defined as a biochemical relapse, ie, an elevation in PSA level in the serum. At this time, PSA level elevation was followed by clinical relapse, ie, distant metastases or local recurrence, in the majority of cases. The usage of elevated $(0.2 \mathrm{ng} / \mathrm{ml}$ or greater) PSA as a first indicator for imminent local or distant recurrent disease has been reported by several authors (eg, Kupelian et al, 1996). In this study, a biochemical relapse was defined as (a) two consecutive PSA serum levels $\geq 0.2 \mathrm{ng} / \mathrm{ml}$ with an interval of at least 3 months followed by an elevated PSA $(\geq 0.2$ $\mathrm{ng} / \mathrm{ml}$ ) or (b) a single observation of PSA $>1 \mathrm{ng} / \mathrm{ml}$ followed by an elevated PSA ( $\geq 0.2 \mathrm{ng} / \mathrm{ml}$ ). PSA levels $\geq 0.2 \mathrm{ng} / \mathrm{ml}$ occurring in the first 3 months after radical prostatectomy were not considered a biochemical relapse if followed by undetectable $(<0.1 \mathrm{ng} / \mathrm{ml}) \mathrm{PSA}$ values. The progression-free survival was defined as the interval between the time of surgery and the first elevated PSA serum level ( $\geq 0.2 \mathrm{ng} / \mathrm{ml})$.

\section{CGH}

Isolation of DNA from the formalin-fixed, paraffinembedded tumor material was performed as described before by us (Alers et al, 1997). Briefly, the tissue blocks were counterstained in DAPI $(0.1 \mathrm{mg} / \mathrm{ml}$ in distilled water) and placed under a fluorescence microscope, enabling a precise selection of the tumor area. Microdissection of the tumor areas was performed using a hollow bore coupled to the microscope. Lower boundaries were checked for the presence of tumor on $4 \mu \mathrm{m}$ hematoxylin-eosin-stained tissue sections. Excised material was minced using a fine scalpel, deparaffinized in xylene and ethanol series, and dried. Isolation of DNA from the formalinfixed, paraffin-embedded material was performed using the Puregene DNA isolation kit (Gentra Systems, Minneapolis, Minnesota). Tumor DNA with a fragment size of $<1 \mathrm{~kb}$ was chemically labeled with biotin-ULS or fluorescein-ULS (Kreatech Diagnostics, Amsterdam, the Netherlands; Alers et al, 1999). Tumor DNA with larger DNA fragment sizes was labeled by nick translation with biotin (Nick Translation System, Gibco BRL, Gaithersburg, Maryland) or with green fluorescent nucleotides (Molecular Probes, Leiden, the Netherlands). Likewise, male reference DNA (Promega) was labeled by nick translation with digoxigenin or red fluorescent nucleotides (both from Boehringer Mannheim, Indianapolis, Indiana). The reaction time and the amount of DNAse were adjusted to obtain a matching probe size for reference and tumor DNA. CGH was performed as described previously by us (Alers et al, 1999, 2000, 2001). In brief, 400 ng of labeled archival tumor DNA and $200 \mathrm{ng}$ of reference DNA and $15 \mu \mathrm{g}$ of unlabeled Cot-1 DNA were ethanol precipitated and dissolved in $10 \mu \mathrm{l}$ of hybridization mixture (50\% formamide, $0.1 \%$ Tween-20, and $10 \%$ dextran sulfate in $2 \times$ SSC at pH 7.0). A double amount of archival tumor DNA was used in comparison with fresh reference DNA. This was based on normal versus normal control experiments (Alers et al, 1999). The probe mixture was denatured and hybridized to normal male metaphase chromosomes (Vysis Inc. Downers Grove, Illinois) for 3 days at $37^{\circ} \mathrm{C}$. After washing of the slides, fluorescent detection of the biotin- and digoxigenin-labeled DNA probes was accomplished with avidin-fluorescein isothiocyanate and anti-digoxigenin rhodamine, respectively. Samples were counterstained with 4',6'diamidino-2-phenyl indole in anti-fade solution. CGH analysis was performed with Quips XL software from Vysis (version 3.1.1). Loss of DNA sequences was defined as chromosomal regions where the mean green:red ratio was below 0.85 , while gain was defined as chromosomal regions where the ratio was above 1.15. These threshold values were based on a series of normal controls. On average 10 intact metaphases were used for evaluation of a tumor. This procedure resulted in $\mathrm{CGH}$ profiles with a sensitivity at the chromosome band level (Alers et al, 2000; Kirchhoff et al, 1999).

\section{Statistical Analysis}

The CGH procedure and analysis were done in a coded fashion, ie, the individuals assigning the $\mathrm{CGH}$ status were not aware whether a case concerned a progressor or a nonprogressor. Comparison of clinical characteristics between the two groups was performed using the Mann-Whitney- $U$ test. Also the comparisons of the mean number of aberrant chromosomes per tumor, the comparisons of the mean numbers of chromosomes with losses or gains per tumor, and the relations between gain of $8 q$ and clinical characteristics were evaluated with the Mann- 
Whitney- $U$ test. In one case (progressor 14) both loss and gain occurred on chromosome arm Xq. These were considered separate events. The resection margin status between the two groups was compared using Fisher's exact test. Differences between the two groups concerning individual chromosome arms were also compared using Fisher's exact test. Comparison between percentages of chromosomal alterations between groups were only performed if the alteration occurred in $\geq 25 \%$ of cases in at least one of the two groups. Multivariate analysis was performed using exact logistic regression. $P=0.05$ (two-sided) was taken as the limit of significance; a $p$ value between 0.05 and 0.10 was considered a statistical trend.

\section{References}

Alcaraz A, Takahashi S, Brown JA, Herath JF, Bergstralh EJ, Larson-Keller JJ, Lieber MM, and Jenkins RB (1994). Aneuploidy and aneusomy of chromosome 7 detected by fluorescence in situ hybridization are markers for poor prognosis in prostate cancer. Cancer Res 54:3998-4002.

Alers JC, Krijtenburg PJ, Hop WCJ, Bolle WABM, Schröder $\mathrm{FH}$, van der Kwast ThH, Bosman FT, and van Dekken $\mathrm{H}$ (1998). Longitudinal evaluation of cytogenetic aberrations in prostatic cancer: Tumours that recur in time display an intermediate genetic status between non-persistent and metastatic tumours. J Pathol 185:273-283.

Alers JC, Krijtenburg PJ, Rosenberg C, Hop WCJ, Verkerk AM, Schröder FH, van der Kwast ThH, Bosman FT, and van Dekken H (1997). Interphase cytogenetics of prostatic tumor progression: Specific chromosomal abnormalities are involved in metastasis to the bone. Lab Invest 77:437-448.

Alers JC, Krijtenburg PJ, Vis AN, Hoedemaeker RF, Wildhagen MF, Hop WCJ, van der Kwast ThH, Schröder FH, Tanke $\mathrm{HJ}$, and van Dekken H (2001). Molecular cytogenetic analysis of prostatic adenocarcinomas from screening studies: Early cancers may contain aggressive genetic features. Am J Pathol 158:399-406.

Alers JC, Rochat J, Krijtenburg PJ, Hop WCJ, Kranse R, Rosenberg C, Tanke HJ, Schröder FH, and van Dekken H (2000). Identification of genetic markers for prostate cancer progression. Lab Invest 80:931-942.

Alers JC, Rochat J, Krijtenburg PJ, van Dekken H, Raap AK, and Rosenberg C (1999). Universal linkage system (ULS): An improved method for labeling archival DNA for comparative genomic hybridization. Genes Chromosomes Cancer 25: 301-305.

Bova GS, Carter B, Bussemakers MJ, Emi M, Fujiwara $Y$, Kyprianou N, Jacobs SC, Robinson JC, Epstein JI, Walsh PC, and Isaacs WB (1993). Homozygous deletion and frequent allelic loss of chromosome 8 p22 loci in human prostate cancer. Cancer Res 53:3869-3873.

Brothman AR, Maxwell TM, Cui J, Deubler DA, and Zhu XL (1999). Chromosomal clues to the development of prostate tumors. Prostate 38:303-312.

Brothman AR, Peehl DM, Patel AM, MacDonald GR, McNeal JE, Ladega LE, and Schellhammer PF (1991). Cytogenetic evaluation of 20 cultured primary prostatic tumors. Cancer Genet Cytogenet 55:79-84.

Bubendorf L, Kononen J, Koivisto P, Schraml P, Moch H, Gasser TC, Willi N, Mihatsch MJ, Sauter G, and Kallioniemi
O-P (1999). Survey of gene amplifications during prostate cancer progression by high-throughput fluorescence in situ hybridization on tissue microarrays. Cancer Res 59:803-806.

Cabeza-Arvelais Y, Thompson TC, Sepulveda JL, and Chinault AC (2001). LAPSER1: a novel candidate tumor suppressor gene from 10q24.3. Oncogene 20:6707-6717.

Cher ML, Bova GS, Moore DH, Small EJ, Carroll PR, Pin SS, Epstein JI, Isaacs WB, and Jensen RH (1996). Genetic alterations in untreated metastases and androgenindependent prostate cancer detected by comparative genomic hybridization. Cancer Res 56:3091-3102.

Cooney KA, Wetzel JC, Meravjer SD, Macoska JA, Singleton TP, and Woyno KJ (1996). Distinct regions of allelic loss on $13 q$ in prostate cancer: Cancer Res 56:1142-1145.

Cunningham JM, Shan A, Wick MJ, McDonnell SK, Schaid DJ, Tester DJ, Qian J, Takahashi S, Jenkins RB, Bostwick DG, and Thibodeau SN (1996). Allelic imbalance and microsatellite instability in prostatic adenocarcinoma. Cancer Res 56:4475-4482.

Dong J-T, Chen C, Stultz BG, Isaacs JT, and Frierson HF (2000). Deletion of $13 q 21$ is associated with aggressive prostate cancers. Cancer Res 60:3880-3883.

Gittes RF (1991). Carcinoma of the prostate. N Eng J Med 324:236-245.

Gleason DF (1992). Histologic grading of prostate cancer. Hum Pathol 23:273-279.

Hermanek P, Hutter RVP, Sobin LH, Wagner G, and Wittekind Ch (1997). TNM atlas. Illustrated guide to the TNM/ pTNM classification of malignant tumors, 4th ed. Berlin: Springer Verlag, 272-280.

Huang SF, Xiao S, Renshaw AA, Loughlin KR, Hudson TJ, and Fletcher JA (1996). Fluorescence in situ hybridization evaluation of chromosome deletion patterns in prostate cancer. Am J Pathol 149:1565-1573.

Jenkins RB, Qian J, Lieber MM, and Bostwick DG (1997). Detection of c-myc oncogene amplification and chromosomal anomalies in metastatic prostatic carcinoma by fluorescence in situ hybridization. Cancer Res 57:524-531.

Kirchhoff M, Gerdes T, Maahr J, Rose H, Bentz M, Döhner H, and Lundsteen C (1999). Deletions below 10 megabasepairs are detected in comparative genomic hybridization by standard reference intervals. Genes Chromosomes Cancer 25: 410-413.

Kupelian P, Katcher J, Levin H, Zippe C, and Klein E (1996). Correlation of clinical and pathologic factors with rising prostate-specific antigen profiles after radical prostatectomy alone for clinically localized prostate cancer. Urology 48: 249-260.

Li C, Berx G, Larsson C, Auer G, Aspenblad U, Pan Y, Sundelin $B$, Ekman $P$, Nordenskjöld $M$, van Roy $F$, and Bergerheim USR (1999). Distinct deleted regions on chromosome segment 16q23-24 associated with metastases in prostate cancer. Genes Chromosomes Cancer 24:175-182.

Lundgren R, Mandahl N, Heim S, Limon J, Henrikson H, and Mitelman $F$ (1992). Cytogenetic analysis of 57 primary prostatic adenocarcinomas. Genes Chromosomes Cancer 4:1624.

Macoska JA, Trybus TM, Sakr WA, Wolf MC, Benson PD, Powell I-J, and Pontes JE (1994). Fluorescence in situ hybridization analysis of $8 p$ allelic loss and chromosome 8 
instability in human prostate cancer. Cancer Res 54:38243830 .

Matsuyama H, Pan Y, Oba K, Yoshihiro S, Matsuda K, Hägarth L, Kudren D, Naito K, Bergerheim USR, and Ekman $P$ (2001). Deletions on chromosome 8p22 may predict disease progression as well as pathological staging in prostate cancer. Clin Cancer Res 7:3139-3143.

McMenamin ME, Soung P, Perera S, Kaplan I, Loda M, and Sellers WR (1999). Loss of PTEN expression in paraffinembedded primary prostate cancer correlates with high Gleason score and advanced stage. Cancer Res 59:42914296.

Nupponen NN, Kakkola L, Koivisto P, and Visakorpi T (1998). Genetic alterations in hormone-refractory recurrent prostate carcinomas. Am J Pathol 153:141-148.

Perinchery G, Bukurov N, Nakajima K, Chang J, Li L-C, and Dahiya R (1999). High frequency of deletion on chromosome 9 p21 may harbor several tumor-suppressor genes in human prostate cancer. Int J Cancer 83:610-614.

Potosky AL, Miller BA, Albertsen PC, and Kramer BS (1995). The role of increasing detection in the rising incidence of prostate cancer. JAMA 273:548-552.

Quinn DI, Henshall SM, Head DR, Golovsky D, Wilson JD, Brenner PC, Turner JJ, Delprado W, Finlayson JF, Stricker PD, Grygiel JJ, and Sutherland RL (2000). Prognostic significance of p53 nuclear accumulation in localized prostate cancer treated with radical prostatectomy. Cancer Res 60: 1585-1594.

Reiter RE, Gu Z, Watabe T, Thomas G, Szigeti K, Davis E, Wahl M, Nisitani S, Yamashiro J, Le Beau MM, Loda M, and Witte ON (1998). Prostate stem cell antigen: A cell surface marker overexpressed in prostate cancer. Proc Natl Acad Sci USA 95:1735-1740.

Saramaki O, Willi N, Bratt O, Gasser TC, Koivisto P, Nupponnen NN, Bubendorf L, and Visakorpi T (2001). Amplification of EIF3S3 gene is associated with advanced stage in prostate cancer. Am J Pathol 159:2089-2094.

Saric T, Brkanac Z, Troyer DA, Padalecki SS, Sarosdy M, Williams K, Abadesco L, Leach RJ, and O'Connell P (1999). Genetic pattern of prostate cancer progression. Int $\mathrm{J}$ Cancer 81:219-224.

Sato K, Qian J, Slezak JM, Lieber MM, Bostwick DG, Bergstralh EJ, and Jenkins RB (1999). Clinical significance of alterations of chromosome 8 in high-grade, advanced, nonmetastatic prostate carcinoma. J Natl Cancer Inst 91:15741580.
Schröder $\mathrm{FH}$, van der Maas $\mathrm{P}$, Beemsterboer $\mathrm{P}$, Boeken Kruger A, Hoedemaeker R, Rietbergen J, and Kranse R (1998). Evaluation of the digital rectal examination as a screening test for prostate cancer. Rotterdam section of the Eur Randomized Study of Screening for Prostate Cancer. J Natl Cancer Inst 90:1817-1823.

Takahashi S, Qian J, Brown JA, Alcaraz A, Bostwick DG, Lieber MM, and Jenkins RB (1994). Potential markers of prostate cancer aggressiveness detected by fluorescence in situ hybridization. Cancer Res 54:3574-3579.

Tsuchiya N, Kondo Y, Takahashi A, Pawar H, Qian J, Sato K, Lieber MM, and Jenkins RB (2002). Mapping and gene expression profile of the minimally overrepresented 8q24 region in prostate cancer. Am J Pathol 160:1799-1806.

Ueda T, Komiya A, Emi M, Suzuki H, Shiraishi T, Yatani R, Masai M, Yasuda K, and Ito $H$ (1997). Allelic loss on 18q21 are associated with progression and metastasis in human prostate cancer. Genes Chromosomes Cancer 20:140-147.

van Dekken $\mathrm{H}$, Rosenberg C, Krijtenburg PJ, and Alers JC (1997). Interphase cytogenetics and comparative genomic hybridization of human epithelial cancers and precursor lesions. Histochem Cell Biol 108:409-430.

van den Berg C, Guan X-Y, von Hoff D, Jenkins R, Bittner M, Griffin C, Kallioniemi O, Visakorpi T, McGill J, Herath J, Epstein J, Sarosdy M, Meltzer P, and Trent J (1995). DNA sequence amplification in human prostate cancer identified by chromosome microdissection: Potential prognostic implications. Clin Cancer Res 1:11-18.

van Weerden WM, de Ridder CMA, Verdaasdonk CL, Romijn $\mathrm{JC}$, van der Kwast ThH, Schröder FH, and van Steenbrugge GJ (1996). Development of seven new human prostate tumor xenograft models and their histopathological characterization. Am J Pathol 149:1055-1062.

Visakorpi T, Kallioniemi AH, Syvänen A-C, Hyytinen ER, Karhu R, Tammela T, Isola JJ, and Kallioniemi O-P (1995). Genetic changes in primary and recurrent prostate cancer by comparative genomic hybridization. Cancer Res 55:342-347.

Visser O, Coebergh JWW, Schouten LJ, and van Dijck JAAM (2001). Incidence of cancer in the Netherlands 1997. Utrecht: Vereniging van Integrale Kankercentra 25:29.

Vocke CD, Pozzatti RO, Bostwick DG, Florence CD, Jennings SB, Strup SE, Duray PH, Lioatta LA, Emmert-Buck MR, and Linehan WM (1996). Analysis of 99 microdissected prostate carcinomas reveals a high frequency of allelic loss on chromosome 8p12-p21. Cancer Res 56:2411-2416. 